\title{
The sensitive period: transfer of fixation after occlusion for strabismic amblyopia
}

\author{
AHMAD A. ASSAF \\ From the Department of Ophthalmology, University of Sheffield
}

SUMMARY Of 2649 patients with strabismic amblyopia who attended clinics between 1941 and 1978, 1904 patients were reviewed. Of these, 115 patients had transfer of fixation after occlusion. These were analysed according to the type of transfer of fixation and relation to occlusion and age. The period of maximum sensitivity to short periods of occlusion extended to 18 months, declining to about 30 months of age. Sensitivity to occlusion reaches low levels about the age of 5 to $5 \frac{1}{2}$ years, though it is still present to some degree, especially in patients with relatively good visual acuity of $6 / 36$ or better. The upper limit of the sensitive period was found to be about the end of the seventh year of age.

There is a clearly defined period during early postnatal life of experimental animals during which the visual system is particularly susceptible to alterations in the visual experience. A few days of visual deprivation during the early life of kittens ${ }^{12}$ and monkeys ${ }^{3-8}$ resulted in amblyopia and histological changes in the lateral geniculate body and the visual cortex.

In man the situation is less clear. Clinical experience indicates that stimulus deprivation amblyopia in children can result from opacities in the media or other forms of visual deprivation.

Congenital cataracts are known to be associated with poor vision. ${ }^{9-11}$ Children with bilateral congenital cataracts, if treated and corrected early, have better visual results. ${ }^{12}$ In unilateral cases it is generally agreed that early correction does not seem to have an effect on the visual outcome, but some authors have reported better visual results with early treatment and correction. ${ }^{1314}$ If deprivation in patients with unilateral cataract occurs between 6 and 30 months of age, counting fingers is the best visual acuity achieved. If deprivation starts between 3 and 10 years of age, visual acuity decreases at a slower rate and is more likely to respond to total full-time occlusion. ${ }^{14}$ Occlusion in these patients is most effective before the age of 4 years.

Von Noorden and Maumenee ${ }^{15}$ observed that amblyopia is more likely in patients who develop cataracts before the age of 6 years, with reversible amblyopia up to the age of 4 to 6 years. Von Noorden

Correspondence to Professor A. A. Assaf, FRCS, Kuwait University, Department of Surgery, PO Box 24923, Kuwait. stated that the upper limit of the sensitive period is 51 months ${ }^{16}$ and that amblyopia is reversible up to the age of 5 years. ${ }^{5}$ A more recent view is that the age of sensitivity may extend from birth to approximately 7 years of age and is greatest in the first 2 years of life. ${ }^{17}$ Von Noorden and Crawford ${ }^{18}$ suggest that the plastic age may extend from birth to the end of the fifth year of life and amblyopia rarely occurs after traumatic cataract in children as old as 7 years. It has been found that corneal opacities after 7 years of age have no significant influence in the development of amblyopia and fixation patterns after keratoplasty. ${ }^{19}$

Awaya et al. ${ }^{20}$ reviewed 19 cases of amblyopia with a history of unilateral occlusion of the eye (mostly for about one week following lid surgery). Sixteen cases were within 13 months of age. The remaining 3 were within 36 months of age. In another article Awaya et $a .^{21}$ reviewed a total of 100 cases of occlusion amblyopia after correction of entropion or other minor lid surgery, after unilateral congenital or traumatic cataract, or after small punctate posterior polar cataract or linear scar of the corneal endothelium and found no irreversible decrease in visual acuity in patients who had short-term lid closure after 18 months of age, with a peak effect between 6 and 9 months. For longer periods of occlusion the critical period may extend to 24 months of age. When occlusion of the sound eye was started before the ninth year of age, visual recovery was poor in approximately $50 \%$ of cases, and all the patients who started occlusion of the sound eye after 9 years of age had showed a poor recovery of their visual acuity. 
Visual evoked responses (VER) have been used as a reliable estimate for measuring visual acuity in infants. ${ }^{22}{ }^{23}$ They can also give valuable information on the development of vision in man. ${ }^{24} 25$ From the visual evoked response it is generally agreed that the visual system in man undergoes rapid maturation in the first year of life, and the visual acuity approximates adult level by 24 months of age. In the same way the amplitude and wave form of VER change to that of adult configuration by 24 months of age ${ }^{26}$ However, Sokol and Jones ${ }^{25}$ reported that minor changes in VER wave form continue until the age of 5 to 6 years and there is little change after 7 years. Arden and Barnard ${ }^{26}$ using VER found that the plasticity of the visual system is retained till the age of 5-11 years.

Interocular transfer (IOT) of the tilt after-effect was used to assess binocularity. It is highly correlated with stereopsis, which is a common clinical index of binocular function. By relating the degree of IOT of the tilt after-effect to the date at which strabismus was first seen and corrected the strabismus was found to have maximum effect on this measurement between 1 and 3 years of age, and continues with exponentially decreasing strength until the age of 8 years. ${ }^{27}$ These authors suggested that immediate corrective surgery is not necessary to maintain cortical binocularity when the esotropia is of late onset, of 4 years and over. Also, by measuring IOT in children whose squint developed at different ages but was corrected by surgery, the end of the critical period for the development of the binocular vision in man was found to be about $2-2.6$ years. $^{28}$

\section{RESPONSE TO OCCLUSION}

Occlusion has long been used in the treatment of strabismic amblyopia and other forms of amblyopia in children. It has also been known that response to occlusion was dependent on age. ${ }^{92930}$ Occlusion amblyopia and transfer of fixation sometimes occurs during occlusion therapy for strabismus; this has been recognised since $1948 .^{9}$ Hardesty ${ }^{31}$ states that over 6 years of age there was probably no danger of producing occlusion amblyopia of a marked degree with patching for several months. Other various authors reported or reviewed similar cases after occlusion, though in general not great in numbers. Goodier ${ }^{32}$ reviewed 21 patients over 3 years old; none were older than 5 years.

The fact that a switch of fixation occurs at all, especially if it either requires occlusion for its reversal (temporary) or is not affected by such occlusion (permanent switch), implies that the neurological mechanisms of fixation must be of sufficient plasticity in those patients to permit considerable realignment. The evidence suggests, as expected, that this plasticity is greater in young children, who require less occlusion, than in older children to produce a switch of fixation, but can nevertheless be present sufficiently in some children up to a certain age.

This article is a report on 115 patients who had transfer of fixation, with or without amblyopia, who were studied in an attempt to define the sensitive period in man. The type of transfer of fixation, whether transient, temporary, or permanent, may be an important indicator of susceptibility to occlusion. Other factors related to the transfer of fixation, such as visual acuity, binocular single vision before and after occlusion, refractive errors, etc., will be dealt with in a subsequent publication.

\section{Materials and methods}

All the patients recorded under the heading of strabismic amblyopia in the Orthoptic Department of the Sheffield Area Health Authority (Teaching) were reviewed. Patients were selected on the following criteria:

(1) Before occlusion a measurable strabismus had been present, without alternation of fixation.

(2) Occlusion had been either: (a) total continuous occlusion of light and form as a patch; $(b)$ intermittent or partial physical occlusion, sometimes with periods of total continuous occlusion.

Patients who had other than physical occlusion at any stage were not included in the analysis, but in view of the particular interest of those in whom the transfer of fixation was not reversible, one such patient who had had atropine occlusion during part of his occlusion period is included in the analysis; another patient in whom the type of occlusion was unknown was included in the $b$ category.

(3) After occlusion there was transfer of fixation, without alternation, to the nonoccluded eye for either a limited period or until the patient was discharged.

The selected patients were analysed according to whether the transfer of fixation was $(a)$ transient, that is, reversed to the original fixation or alternated without further occlusion, in subsequent visit or visits; (b) temporary, that is, reverted to the original fixation or alternates after various forms of occlusion of the newly fixing eye; $(c)$ permanent, that is, reversed squint permanently to the originally fixing eye.

A total of 2649 patients were listed under the heading of strabismic amblyopia, but only 1904 notes were found. These patients attended during the period 1941-78, when the study was initiated. Though some were still attending at the time of review, the final outcome of occlusion could be determined.

\section{Results}

One hundred and fifteen patients fitted the criteria for transfer of fixation, 25 had transient switch of fixation, 


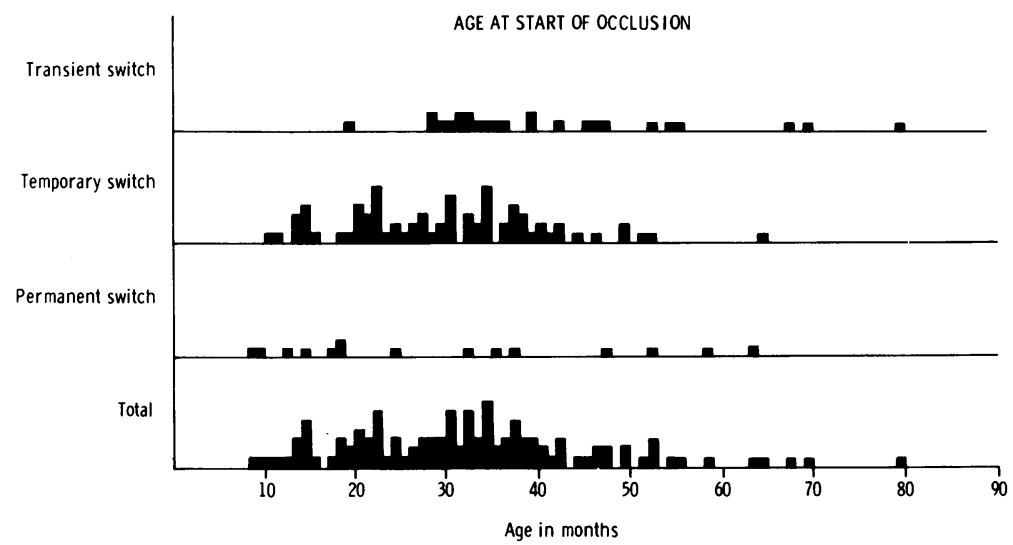

Fig. 1 Age at the start of occlusion for patients with transfer of fixation according to the type of switch. Most were under $5^{1 / 2}$ years of age, and older patients tended to have transient switch. The number of the patients at the younger end of this figure is probably determined by the number of patients occluded at such an early age rather than by sensitivity to occlusion.

75 had temporary switch, and 15 had permanent switch.

In 48 of the 75 patients with temporary switch further occlusion was delayed until further visit or visits which confirmed the transfer of fixation, but 27 patients were treated by immediate occlusion of the fixing eye. Some of these might, if left without occlusion, have shown only transient switch of fixation, so the distinction between transient and temporary switch is somewhat blurred.

Of the 15 patients with permanent switch only 5 never switched back or alternated with further occlusion. The remainder switched back at some time to the originally squinting eye, but, after further different types and methods of occlusion, switched back to have strabismus in the originally good eye for a few years before discharge.

TYPE OF OCCLUSION

Transfer of fixation may follow either total continuous occlusion or various combinations of partial or intermittent occlusion. The majority of the latter had a period of initial total continuous occlusion, then had a break in occlusion or changed to milder forms. There is an apparent tendency for patients with permanent transfer to follow partial and/or intermittent occlusion (Table 1).

In 2 patients in the temporary group and two in the permanent group transfer of fixation followed surgery

Table 1 Type of occlusion and the type of switch

\begin{tabular}{llcr}
\hline Type of occlusion & \multicolumn{2}{l}{ Pattern of switch of fixation } & Total \\
\cline { 2 - 3 } & $\begin{array}{l}\text { Transient or } \\
\text { temporary }\end{array}$ & Permanent & \\
\hline Total continuous occlusion & 59 & 4 & 63 \\
$\begin{array}{l}\text { Partial and/or intermittent } \\
\text { occlusion }\end{array}$ & 41 & 11 & 52 \\
Total & 100 & 15 & 115 \\
\hline
\end{tabular}

on the originally fixing eye, the squint having become alternating. There were no surgical complications, and presumably the change in fixation was due to lid swelling, photophobia, or lid closure acting as a temporary form of occlusion.

\section{AGE OF BEGINNING OCCLUSION}

The age of occlusion of 115 patients ranged from 9 months to 6 years and 8 months (Fig. 1), with a mean of 33 months. Abot $88 \%$ of the patients were aged 4 years or less. A total of 14 patients switched fixation at an age of occlusion of over 4 years. All except 4 had a relatively good visual acuity of $6 / 36$ or better in the amblyopic eye at the start of occlusion. One of those 4 was aged 5 years and 4 months and had a permanent switch of fixation after 7 successive months of mostly total continuous occlusion.

The age of occlusion for the patients with permanent switch of fixation ranged from 9 months to 5 years and 4 months, with a mean of 25 months. Those with temporary switch had a mean of 31 months. Patients with transient switch had a mean of 37 months. The last group were on average older than the other 2 .

\section{AGE OF TRANSFER OF FIXATION}

The age of transfer of fixation was taken as the age at the midpoint of the period of occlusion during which the transfer occurred. This ranges from 9 months to 6 years and 10 months (Fig. 2). The graph for the age of switch of fixation (Fig. 3) shows that the peak of the permanent switch cases was in the second year of life, the temporary switch cases at the third year, and those of the transient switch at the fourth year of life. Fig. 2 shows only that one patient had transient switch of fixation below the age of 30 months, and this patient, at the age of 20 months, had only one week of total continuous occlusion. So younger patients tended, if they transferred fixation at all, to have at 
Fig. 2 Age at transfer of fixation taken as the age at the middle of the last period of occlusion immediately before the visit during which switch of fixation was demonstrated. Most patients were under 6 years of age.

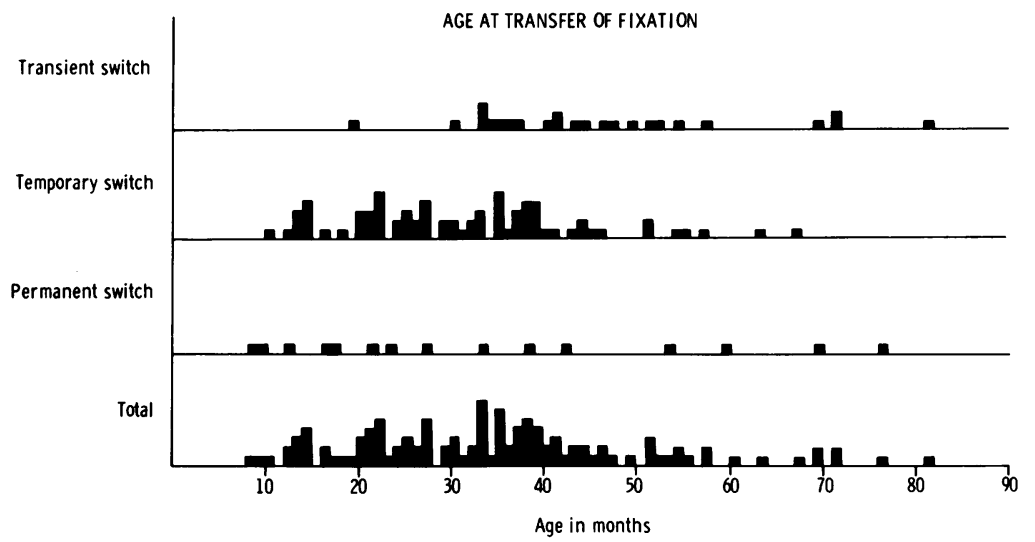

least a temporary, if not a permanent, transfer. All the 3 groups showed a decrease in the number of patients at the end of the fifth year of life.

\section{DURATION OF OCCLUSION}

The relationship between the duration of occlusion and the age of occlusion cannot be usefully assessed in those patients who had various forms of intermittent and/or partial occlusion. The relationship in those who had continuous total occlusion is shown in Fig. 4. The continuous line shows the period of occlusion during which the change of fixation occurred, its upper end giving the total period of occlusion: switch of fixation could have occurred at any time during this visit. This figure shows a wide range of scatter, but this could be explained by variations in the state of visual acuity and fixation before occlusion, binocular single vision, refractive state, duration of squint, and the type of switch produced, in addition to how strictly the patient carried out the instructions for total continuous occlusion.

Nevertheless, there is an obvious relationship between the age of occlusion and the duration of occlusion, the reversal of fixation occurring quicker in the younger age group. The youngest patient to switch after total continuous occlusion was 10 months and the oldest was 4 years and 7 months at the start of occlusion. Most of the patients below 2 years of age switched fixation after one visit of total continuous occlusion and mostly within 2 weeks of occlusion. There is a noticeable increase in resistance to occlusion after this period, and resistance to occlusion reaches high levels after the age of 4 years.

Children with permanent switch of fixation are in many ways the most interesting, since it implies that permanent damage could be produced to fixation and visual acuity. All these patients had energetic occlusion in an attempt to reverse the transfer of fixation. The age of occlusion at which switch occurred in this group extended to 64 months of age (Fig. 5), and the age of transfer extended to 77 months of age. Patients under the age of 18 months needed a relatively short time of occlusion to transfer fixation. Four patients with permanent transfer switched after total continuous occlusion only; all were below the age of 18 months.

Five of these patients never switched back or

\section{AGE AT TRANSFER OF FIXATION}

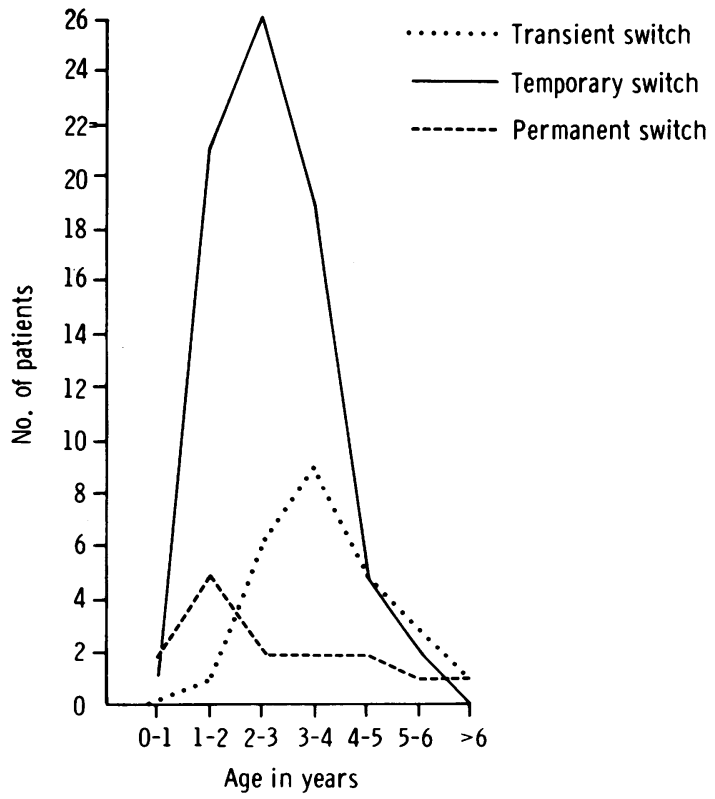

Fig. 3 Graph of the age at transfer of fixation according to type of switch. Notice patients with permanent switch of fixation had a peak age between 1-2 years. Temporary switch patients between 2-3 vears and those with transient switch between 3-4 years of age. 


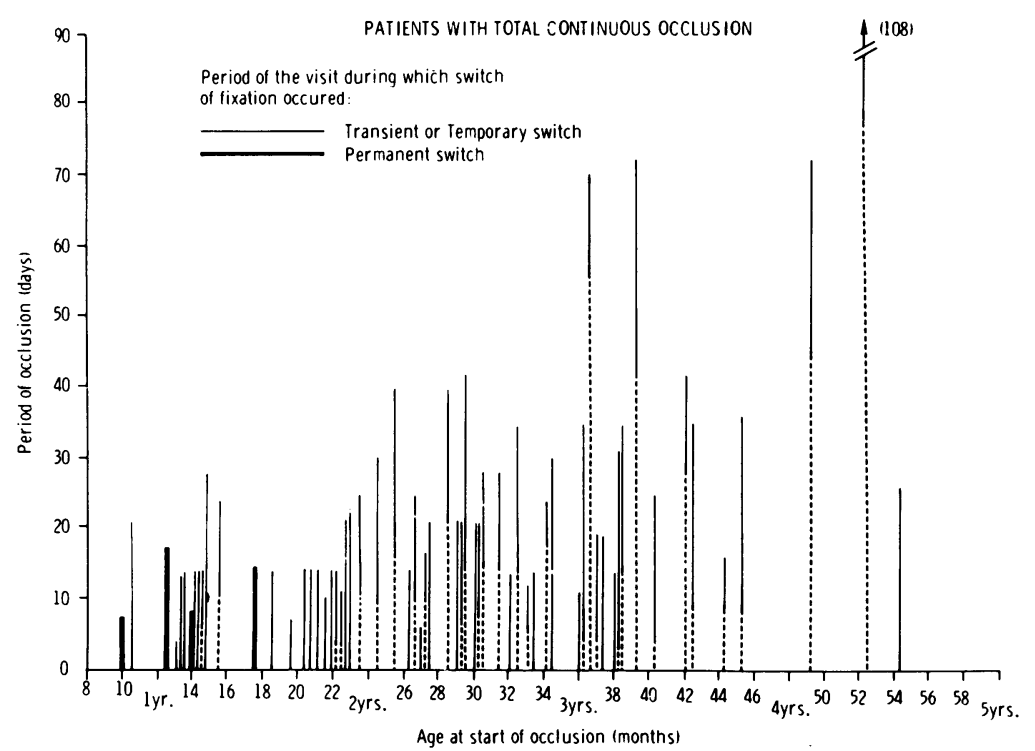

Fig. 4 Patients who switched fixation after total continuous occlusion only. Four patients under the age of 18 months had permanent switch, all other patients had either temporary or transient switch. The duration of occlusion increases with age, with variations which could be explained in most cases by the refractive state, visual acuity, and fixation prior to occlusion and the type of switch produced. None of the patients were older than $4 \frac{1}{2}$ years.

alternated after the initial transfer of fixation, in spite of reversal of occlusion, indicating a considerable damage to the fixation mechanisms. Three of these patients were below 14 months of age and 2 had obvious prolonged periods of occlusion (Fig. 5).

\section{Discussion}

It must be remembered that this is a retrospective study and therefore subject to the limitations of any such study. Moreover, the exact type and duration of occlusion was determined by the individual orthoptist concerned, subject to the general policy of the department, and may therefore have varied considerably between orthoptists and at different times. The intervals between visits during occlusion was sometimes quite long, sometimes doubtless due to the failure of the patient to attend, so that the exact duration before switch of fixation occurred is sometimes rather uncertain.

Development of fixation mechanisms on the other hand is a separate process from development of many other visual functions, and its process of maturation may or may not reflect the general maturation of the visual system. Nevertheless some conclusions can be tentatively drawn.

The period of susceptibility to switch of fixation after occlusion was found to be between 9 months and 6 years and 10 months of age. The lower limit is probably determined in this study by the number of patients occluded at such an early age rather than by the sensitivity to occlusion during this period, which can be outlined as follows:
The most sensitive part (critical period) was up to 18 months of age, with patients under 14 months being the more so. Considerable sensitivity extends to 24 or 30 months of age. This is supported by:

(a) The 3 patients under 14 months of age in the permanent switch group, switched fixation after short period of occlusion and never switched back or alternated. (b) Four patients who had permanent switch of fixation after total continuous occlusion were under 18 months of age. (c) Those patients below 18 months of age in the permanent switch group needed relatively shorter periods of occlusion to switch. (d) Most of the patients under 2 years old in the total continuous occlusion patients switched fixation within one visit and mostly within 2 weeks of occlusion. (e) The peak of permanent switch group was in the second year of life. (f) Transfer of fixation below 30 months of age was permanent or temporary rather than transient.

These findings fit those in previous reports. ${ }^{141720212628}$ This is also supported by the findings that most of the human visual system appears to be anatomically adult by the age of two years. ${ }^{33}$

The sensitivity reaches low levels at about the age of 5 to $5 \frac{1}{2}$ years (after the fourth year) of life, though still present to some degree, especially in patients with relatively good visual acuity of $6 / 36$ or better. This is supported by:

(a) Few patients switched fixation beyond 5-51/2 years of age. (b) Few patients switched fixation with total continuous occlusion after 4 years of age. (c) All patients with permanent switch of fixation had their age of start of occlusion below $5 \frac{1}{2} 2$ years. $(d)$ Older 


\section{OCCLUSION TO INITIAL SWITCH IN PATIENTS WITH PERMANENT TRANSFER OF FIXATION}

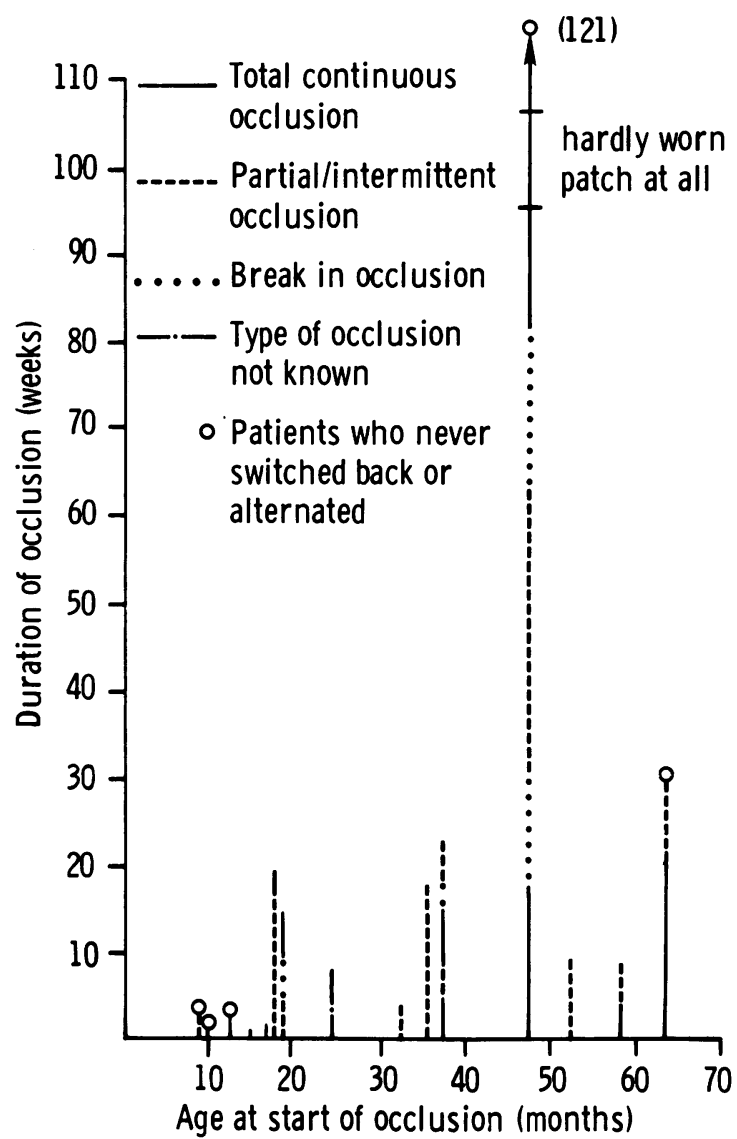

Fig. 5 Period of occlusion in patients with permanent switch of fixation. Patients under 18 months of age had relatively shorter periods of occlusion. Five patients never switched back or alternated, 3 were under 13 months of age, and 2 had prolonged initial total continuous occlusion. None of the patients were older than 51/2 years of age at the start of occlusion.

patients, over 4 years of age, tended to have transient switch and have good visual acuity of $6 / 36$ or better before occlusion.

These findings fit those recorded in previous reports. ${ }^{514-1618252731}$ It might be of interest to mention that the normal human newborn child has a typical brain mass of $350 \mathrm{~g}$ and at 1 year old of about $500 \mathrm{~g}$, and that the brain, particularly the cerebral cortex, continues to grow rapidly in the first 3 years of life-the period of most rapid learning. By the age of 6 years the mass of the brain is $90 \%$ of its adult value of $1375 \mathrm{~g} .{ }^{34}$ This, though, indicates that the general development of the brain may have a relation to the development of the visual system.

The upper limit of the sensitive period is about the end of the seventh year of age. This fits previously reported findings. ${ }^{17-19} 2527$

I am indebted to Mr Alan Stanworth for his encouragement and valuable contributions and comments all through this article. My thanks also to Mr A. J. Dark. Mr I. M. Strachan and other consultant staff at the Royal Hallamshire Hospital for encouragement and for allowing me to include their patients. to Mr R. Mapstone for his encouragement and to Orthoptic Department staff for their co-operation.

\section{References}

1 Hubel DH, Weisel TN. The period of susceptibility to physiological effects of unilateral lid closure in kittens. J Physiol 1970; 206: 419-36.

2 Wilkinson FE. Reversal of the behavioural effects of monocular deprivation as a function of age in kittens. Behav Brain Res 1980; 1: 101-23.

3 Baker FH, Grigg P, von Noorden GK. Effects of visual deprivation and strabismus on response of neurons in the visual cortex of the monkey, including studies on the striate and peristriate cortex in normal animals. Brain Res 1974; 66: 185-208.

4 Crawford ML, Blake R, Cool SJ, von Noorden GK. Physiological consequences of unilateral and bilateral eye closure in Macaque monkeys. Some further observations. Brain Res 1975; 84: 150-4.

5 von Noorden GK. Experimental amblyopia in monkeys. Further behavioural observations and clinical correlations. Invest Ophthalmol Visual Sci 1973; 12: 721-6.

6 von Noorden GK. Histological studies of the visual system in monkeys with experimental amblyopia. Invest Ophthalmol Visual Sci 1973 ; 12: 727-38.

7 von Noorden GK, Crawford MLJ. Morphological changes in the monkeys visual system after short term lid suture. Invest Ophthalmol Visual Sci 1978; 17: 762-768.

8 von Noorden GK, Dowling JE, Ferguson DC. Experimental amblyopia in monkey. I. Behavioural studies of stimulus deprivation amblyopia. Arch Ophthalmol 1970; 84: 206-14.

9 Costenbader F, Bain D, McPhail A. Vision in strabismus. preliminary report. Arch Ophthalmol 1948; 40: 438-53.

10 Leinfelder JP. Amblyopia associated with congenital cataract. Am J Ophthalmol 1963; 55: 527-9.

11 Owen WC, Hughes WF Jr. Results of treatment of congenital cataract. Arch Ophthalmol 1948; 39: 339-50.

12 Taylor D, Vaegan, Morris JA, Rogers JE, Warland J. Amblyopia in bilateral infantile and juvenile cataract. Relationship to timing of treatment. Trans Ophthalmol Soc UK 1979; 99: 170-5.

13 Campos EC, Enoch JM, Robinowicz MI. In: Reinecke RD, ed. Proc III Meeting Int Strab Ass. New York: Grune and Stratton, 1978: 319-25.

14 Vaegan, Taylor D. Critical period for deprivation amblyopia in children. Trans Ophthalmol Soc UK 1979; 99: 432-9.

15 von Noorden GK, Maumenee AE. Clinical observations on stimulus deprivation amblyopia. Am J Ophthalmol 1968; 65: $220-4$.

16 von Noorden GK. Factors involved in the production of amblyopia. Br J Ophthalmol 1974; 58: 158-64.

17 von Noorden GK. Primate model for amblyopia. In: Reinecke RD, ed. Proc III Meeting Int Strab Ass. New York: Grune and Stratton, 1978: 23-29.

18 von Noorden GK, Crawford MLJ. The sensitive period. Trans Ophthalmol Soc UK 1979; 99: 442-6.

19 Singh G, Das PN. Pattern of amblyopia and fixation after keratoplasty. Br J Ophthalmol 1978; 62: 29-33. 
20 Awaya S, Miyake Y, Imaizumi G, Shiose V, Kanda T, Komuro $\mathrm{K}$. Amblyopia in man suggestive of stimulus deprivation amblyopia. Jpn J Ophthalmol 1973; 17: 69-82.

21 Awaya S, Sungawara M, Miyake S. Observations in patients with occlusion amblyopia. Results of treatment. Trans Ophthalmol Soc UK 1979; 99: 447-54.

22 Dobson V, Teller DY. VA in human infants, a review and comparison of behavioural and electrophysiological studies. Vision Res 1978; 18: 1469-83.

23 Linksz A. VA in the newborn with notes on some objective methods to determine VA. Doc Ophthalmol 1973; 34: 259-70.

24 Harter MR, Suitt CD. Visual evoked cortical responses and pattern vision in infants: a longitudinal study. Pschonomic Sci 1970; 18: 235-7.

25 Sokol S, Jones K. Implicit time of pattern evoked potentials in infants: an index of maturation of spatial vision. Vision Res 1979; 19: $747-55$.

26 Arden GB, Barnard WM. Effects of occlusion on the visual evoked response in amblyopia. Trans Ophthalmol Soc UK 1979; 99: 419-26.

27 Banks MS, Aslin RN, Leston RD. Sensitive period for the development of binocular vision. Science 1975; 190: 675-7.

28 Hohmann A, Creutzfeldt OD. Squint and the development of binocularity in humans. Nature $1975 ; 254$ : 613-4.

29 Travers T a'B. Concomitant strabismus. Br J Ophthalmol 1936; 20 (suppl): 44.

30 Yoxall I. Loss of central fixation. Br Orthopt J 1939; 1: 15-9.

31 Hardesty HH. Occlusion amblyopia. Report of a case. Arch Ophthalmol 1959; 62: 314-6.

32 Goodier HM. A survey of patients showing transfer of amblyopia for the originally deviating eye to the originally fixing eye by means of occlusion therapy. Br Orthopt J 1969; 26: 103-10.

33 Haith MM. In: Held R, Leibowitz HW, Teuber HL, eds. Handbook of Sensory Physiology. Berlin: Springer, 1978: 8: Chapter 13: 437.

34 Sagan C. The Dragons of Eden. Sevenoaks: Hodder and Stoughton, 1977: 33-36. 